\title{
1. A human rights-based approach to measuring poverty
}

\author{
Olivier De Schutter
}

A human rights-based approach to poverty is one that goes beyond an identification of unfulfilled needs to address deprivation: it seeks to identify the causes of poverty redefined as the result of a process of exclusion and discrimination. As such, it redefines poverty not simply in static terms, as a condition facing the most disadvantaged segment of the population, but also in dynamic terms as the outcome of societal choices that should be challenged. A human rights-based approach to poverty thus presents a strong relationship to the 'social exclusion' understanding of poverty. This understanding contrasts with an approach focused on incomes, in which an individual is deemed poor if his or her income is insufficient to meet the cost of a basket of food and non-food items essential to be an active participant in society, ${ }^{1}$ and it also contrasts with a multidimensional approach focused on entitlements. Both of these approaches see poverty as a condition facing a group of the population rather than as the outcome of certain policy choices. ${ }^{2}$

Until the mid-1990s, poverty had been defined in purely monetary terms - as a lack of income. It is now seen, instead, as a multidimensional phenomenon, associated with multiple violations of human rights resulting from the lack of entitlement to a number of goods and services that are essential for the enjoyment of rights. ${ }^{3}$ The Programme of Action adopted at the 1995 World Summit for Social Development states that:

Poverty has various manifestations, including lack of income and productive resources sufficient to ensure sustainable livelihoods; hunger and malnutrition; ill health; limited or lack of access to education and other basic services; increased morbidity and mortality from illness; homelessness and inadequate housing; unsafe environments; and social discrimination and exclusion. It is also characterized by a lack of participation in decision-making and in civil, social and cultural life. ${ }^{4}$

1 Martin Ravallion, 'Poverty Lines in Theory and Practice' Living Standards Measurement Study (LSMA) Working Paper $133<$ http://documents1.worldbank.org/curated/en/916871468766156239/pdf/ multi-page.pdf $>$ accessed 30 June 2020.

2 C Gore, 'Introduction: Markets, Citizenship, and Social Exclusion', in C Rodgers, C Gore and JB Figueiredo (eds), Social Exclusion: Rhetoric Reality Responses (Geneva: International Labour Organisation, 1995) 1-2; AM Fischer, Poverty as Ideology. Rescuing Social Justice from Global Development Agendas (London: Zed Books, 2018) ch 5.

3 On the notion of the multidimensional understanding of poverty and its value, see in particular Sabina Alkire and others, Multidimensional Poverty Measurement and Analysis (Oxford: OUP 2015); A Atkinson, Monitoring Global Poverty. Report of the Commission on Global Poverty (World Bank 2017).

4 United Nations World Summit for Social Development, 'Programme of Action of the World Summit for Social Development' UN Doc A/Conf.166/9 (14 March 1995) ch 2 art 19. 
In a statement adopted in 2001, the Committee on Economic, Social and Cultural Rights (CESR) defined poverty as 'a human condition characterized by sustained or chronic deprivation of the resources, capabilities, choices, security and power necessary for the enjoyment of an adequate standard of living and other civil, cultural, economic, political and social rights' ${ }^{5}$

These definitions of poverty frame it as both a cause and a consequence of violations of human rights - whether civil, cultural, economic, political or social rights. ${ }^{6}$ People in poverty not only face numerous obstacles in accessing rights and entitlements (including education, housing, nutritious food, healthcare and work, but also political participation); they also are caught in a vicious cycle in which those deprivations themselves make it more difficult for them to escape poverty. It is this vicious cycle, with its dynamic dimension, that relates poverty to a process of social exclusion. Persons experiencing extreme poverty in particular 'live in a vicious cycle of powerlessness, stigmatization, discrimination, exclusion and material deprivation, which all mutually reinforce one another'?

This is well expressed in the 2005 Principles and Guidelines for a Human Rights Approach to Poverty Reduction Strategies, which describe poverty not only as multidimensional (linked to a range of deprivations) but also as a process in which the various deprivations are 'mutually reinforcing', and associated with 'stigma, discrimination, insecurity and social exclusion'. These Principles and Guidelines conclude that any effective anti-poverty strategy should be defined as a strategy aimed at improving the protection of the human rights of people living in poverty: 'The commitment to ensure respect for human rights will act as a force against all these forms of deprivation'. ${ }^{9}$ This is the only way to break the vicious cycle between poverty and the lack of enjoyment of human rights, thus 'connecting the powerless with the empowering potential of human rights'. ${ }^{10}$

In the context of a human rights-based approach to poverty reduction, poverty should therefore be defined as a process of exclusion that leads to various forms of deprivation that are mutually reinforcing and not only trap individuals into poverty but also lead to an intergenerational transmission of poverty. ${ }^{11}$ The lack of income (monetary poverty) matters of course, but

5 UN Committee on Economic, Social and Cultural Rights (CESCR) 'Substantive Issues Arising in the Implementation of the International Covenant on Economic, Social and Cultural Rights: Poverty and the International Covenant on Economic, Social and Cultural Rights' (10 May 2001) UN Doc E/C.12/2001/10 para 8 .

6 Although the emphasis has generally been on economic, social and cultural rights in the discussion of poverty-reduction policies, the poor also face systematic violations of their civil and political rights, including as a result of police brutality, of excessive subjection to pretrial detention, or denial of voting rights. See UN General Assembly (UNGA), 'Extreme Poverty and Human Rights, Note by the Secretary-General' (4 October 2017) UN Doc A/72/502.

7 Office of the UN High Commissioner for Human Rights (OHCHR), 'Guiding Principles on Extreme Poverty and Human Rights' (27 September 2012) <www.ohchr.org/Documents/Publications/ OHCHR_ExtremePovertyandHumanRights_EN.pdf $>$ accessed 30 June 2020.

8 OHCHR, 'Principles and Guidelines for a Human Rights Approach to Poverty Reduction Strategies' (2005) UN Doc. HR/Pub/06/12 para 15.

9 ibid. For a detailed description of the relationship between poverty and human rights, see OHCHR, 'Human Rights and Poverty Reduction: A Conceptual Framework' (2004) UN Doc HR/Pub/04/01.

10 CESCR (n 5) para 6.

11 On the inter-generational transmission of poverty, see Anna Cristina d'Addio, 'Intergenerational Transmission of Disadvantage: Mobility or Immobility Across Generations? A Review of the Evidence across OECD Countries' (2007) OECD Social, Employment and Migration Working Paper 52; O Causa and A Johansson, 'Intergenerational Social Mobility in OECD Countries' 'OECD Journal: Economic 


\section{Research handbook on human rights and poverty}

so does the lack of access to the goods or services essential to the enjoyment of human rights and which would otherwise allow individuals to escape poverty: housing, education, healthcare, food, work and social security. Ideally, indicators should be developed to track, for each of these, availability (in relation to needs), accessibility (including economic accessibility, physical accessibility, and non-discrimination), and adequacy, in order to identify deprivations that require the most urgent action.

Section I provides further clarifications as to the components of a human rights-based approach to poverty reduction: it considers respectively the principle of accountability, the principle of equality and non-discrimination and the principle of participation, explaining how taking into account these principles can significantly improve the legitimacy and effectiveness of poverty-reduction strategies. Section II then focuses on the role of human rights in guiding poverty measurement, which should not be seen simply as a means to quantify existing levels of poverty in a country but also as a tool to ensure accountability and one which requires not only assessing how many people are poor, but also who the poor are. Section III offers a brief conclusion.

\section{THE ROLE OF HUMAN RIGHTS PRINCIPLES IN SHAPING POVERTY-REDUCTION STRATEGIES}

The Guiding Principles on extreme poverty and human rights (Guiding Principles), which the Human Rights Council endorsed on 27 September 2012 in resolution 21/11, are the most authoritative guidance on how human rights should be taken into account in the fight against poverty. They provide that States should adopt a human rights-based poverty reduction strategy 'that actively engages individuals and groups, especially those living in poverty, in its design and implementation'. ${ }^{2}$ Three human rights principles play a key role in the design and implementation of poverty-reduction strategies thus conceived.

\section{A. Accountability}

A human rights-based poverty reduction strategy sees the adoption of such a strategy not as voluntary for the State but as a legal obligation imposed under its human rights commitments and for which the State must be held accountable. It follows that the strategy should provide beneficiaries with rights that they may claim: once rights are introduced into the context of policymaking

the rationale of poverty reduction no longer derives merely from the fact that the people living in poverty have needs but also from the fact that they have rights - entitlements that give rise to legal obligations on the part of others. Thus, the human rights perspective adds legitimacy to the demand for making poverty reduction the primary goal of policymaking. ${ }^{13}$

Studies' $(2010)<$ https://read.oecd-ilibrary.org/economics/oecd-journal-economic-studies/volume-2010/ issue-1 eco studies-v2010-1-en\#page1> accessed 2 June 2020; Chronic Poverty Research Centre (CPRC), 'Asset Inheritance and IGT of Poverty' <www.chronicpoverty.org/publications/keyword/ Asset + inheritance + and + IGT + of + poverty + series $>$ accessed 2 June 2020.

12 Guiding Principles (n 7) para 50.

13 OHCHR (n 8) para 19. 
It also follows that the implementation of the strategy should be monitored by independent mechanisms, such as national human rights institutions, courts, parliamentary committees and regional and international human rights mechanisms. ${ }^{14}$ For such monitoring to be effective, the strategy should include appropriate indicators (both quantitative and qualitative), benchmarks and timetables (both sufficiently ambitious and realistic), ensuring that progress shall be achieved in accordance with a specific timeline. ${ }^{15}$ It should also include a participatory dimension in order to ensure that the poor themselves are involved in monitoring adequate implementation. ${ }^{16}$

Human rights-based indicators are distinct from macro-economic or development indicators that simply register socio-economic facts. Human rights-based indicators include those that refer to: State commitments or the legal, institutional and policy frameworks that the State establishes (structural indicators); State efforts to ensure that the commitments are effectively implemented, i.e., translated into the adoption of concrete measures and policies (process indicators); and finally, the results achieved (outcome indicators). ${ }^{17}$ These three categories of indicators are interdependent and mutually supportive: the structural indicators ensure that the beneficiaries of measures adopted by the State shall have access to remedies (judicial and non-judicial) and that the State's performance shall be adequately monitored, in particular, by independent bodies (including national human rights institutions). The process indicators ensure that States shall effectively deliver on their promises, in particular by making the required budgetary investments. Finally, the outcome indicators, which present the closest resemblance to development indicators, serve to ensure the policies actually make a difference - that they are having an impact - so that misguided or ineffective policies can be revised and improved.

\section{B. Equality and Non-Discrimination}

It is noteworthy that Article 2(2) of the International Covenant on Economic, Social and Cultural Rights (CESCR) mentions 'social origin' and 'property' among the prohibited grounds of discrimination, alongside, inter alia, race, colour, sex, language or religion. Indeed, the CESCR insists that such grounds should be included in the anti-discrimination framework adopted by the States parties to the Covenant. ${ }^{18}$ In its General Comment No. 20 on non-discrimination, the Committee reiterated that

Individuals and groups of individuals must not be arbitrarily treated on account of belonging to a certain economic or social group or strata within society. A person's social and economic situation when living in poverty or being homeless may result in pervasive discrimination, stigmatization and

Guiding Principles (n 7) paras 103, 107.

ibid 104.

ibid 107.

17 UN International Human Rights Instruments (HRI), 'Report on Indicators for Promoting and Monitoring the Implementation of Human Rights' (6 June 2008) UN Doc HRI/MC/2008/3 (introducing this framework).

18 CESCR, 'Concluding Observations on the Sixth Periodic Report of Canada' (23 March 2016) UN Doc E/C.12/CAN/CO/6 para 17 (referring to 'social condition' as a prohibited ground of discrimination). 


\section{Research handbook on human rights and poverty}

negative stereotyping which can lead to the refusal of, or unequal access to, the same quality of education and health care as others, as well as the denial of or unequal access to public places. ${ }^{19}$

\section{The requirement of equality and non-discrimination in combating poverty}

Protecting the poor against discrimination on the basis of their social condition is key to removing the structural determinants of poverty, because poverty and discrimination are mutually reinforcing: 'Discrimination may cause poverty, just as poverty may cause discrimination'.${ }^{20}$ As regards the homeless for instance, the Special Rapporteur on the right to adequate housing noted that discrimination 'is both a cause and a consequence of homelessness': not only may discrimination result in exclusion and increase the likelihood of a person becoming homeless, but in addition, once homeless, one may experience additional discrimination as a result. ${ }^{21}$ The explicit protection from discrimination on grounds of social condition has symbolic value, sending a clear message to policy-makers that people may not be treated less favourably because they are poor. It also has institutional consequences by allowing Equality Bodies (independent institutions tasked with preventing and addressing discrimination and promoting equality) to contribute more effectively to the fight against poverty, alongside the contributions other human rights mechanisms can make.

In practice however, the requirement to protect people from discrimination on grounds of social status is, at best, highly uneven..$^{22}$ Relying on such a ground of discrimination raises specific challenges, both because the meaning of the socio-economic status ground is poorly understood $^{23}$ and because, in the large majority of cases, discrimination on grounds of social condition (or socio-economic status) is combined with discrimination on other grounds (particularly sex, race or ethnic origin, disability or age), requiring specific methodologies to be developed to address appropriately multiple discriminations. ${ }^{24}$

The potential role of the prohibition of discrimination on grounds of 'social condition' could be maximized by relying on an expanded notion of the concept of 'social origin' which appears in article 2(2) of the International Covenant on Economic, Social and Cultural Rights.

19 CESCR, 'General Comment No. 20: Non-discrimination in Economic, Social and Cultural Rights' (2 July 2009) UN Doc E/C.12/GC/20 para 35.

20 CESCR (n 5) para 11.

21 UNGA, 'Report of the Special Rapporteur on Adequate Housing as a Component of the Right to an Adequate Standard of Living and on the Right to Non-discrimination in this Context' (30 December 2015) UN Doc A/HRC/31/54 para 39.

22 Margaret Thornton, 'Social Status: the last bastion of discrimination' (2018) 1(3) ADLR 1-26.

23 Guidance may be found in the interpretation provided to the prohibition of discrimination based on the term 'social condition', which appears in art 10 of the Charter of Human Rights and Freedoms of the Canadian Province of Québec: "The definition of "social condition" contains an objective component. A person's standing in society is often determined by his or her occupation, income or education level, or family background. It also has a subjective component, associated with the perceptions that are drawn from these various objective points of reference. A plaintiff need not prove that all of these factors influenced the decision to exclude. It will, however, be necessary to show that as a result of one or more of these factors, the plaintiff can be regarded as part of a socially identifiable group and that it is in this context that the discrimination occurred' Comm. des droits de la personn v. Gauthier (1993) 19 C.H.R.R. D/312 [English summary].

24 See Equinet (European Network of Equality Bodies), 'Addressing Poverty and Discrimination: Two Sides of the One Coin' (December 2010) <www.archive.equineteurope.org/IMG/pdf/poverty _opinion_2010_english.pdf $>$ accessed 2 July 2020. 
The CESCR understands this expression to refer to the 'social and economic situation when living in poverty or being homeless'. ${ }^{25}$ As noted by Angelo Capuano, however, this definition may be unnecessarily restrictive and thus potentially irrelevant in many contexts where discriminatory treatment is based. First, the 'social status' of a person 'is reflected more by prestige and esteem rather than merely property status, wealth or economic status'. ${ }^{26}$ Moreover, "the criteria which the CESCR seems to use to give content to the concept of "social status" - property status, caste, and economic and social status such as homelessness and poverty - are not likely to be bases upon which an employer will commonly have the opportunity to discriminate'. ${ }^{27}$ Instead, he suggests, discrimination most frequently occurs on the basis of family relationships, of the schools the person has attended, or of childhood circumstances: these are instances of 'ascribed status', rather than 'achieved status', and it is these instances in particular that one should be devoting more attention to. ${ }^{28}$

\section{The three roles of equality and non-discrimination in combating poverty}

The first implication of the prohibition of discrimination on grounds of social condition or property is that (to borrow from the classic definition of discrimination in human rights law) any distinction, exclusion, restriction or preference or other differential treatment that is based on such grounds and which has the purpose or effect of impairing the enjoyment or exercise of human rights should be prohibited as a form of unlawful discrimination. The reference in Article 2, paragraph 2 of the International Covenant on Economic, Social and Cultural Rights to 'property' (in French: 'fortune') implies that the poor cannot be treated adversely simply because they are poor: in principle, their underprivileged socio-economic situation cannot be allowed to result in a reduced ability to enjoy human rights.

There is an additional and more interesting implication of the prohibition of discrimination on grounds of social origin or property. Human rights law prohibits any action or omission that disproportionately affects members of a particular group, in the absence of a reasonable and objective justification, thus constituting de facto discrimination..$^{29}$ Thus, regulatory or policy measures that are neutral on their face may be considered discriminatory if they do not take into account the disparate impacts they may have on certain groups of the population, defined for instance on the basis of 'property' or income levels. It is this idea that is at the heart of a 'positive duty' to consider the impacts on poverty in law- and policy-making, as imposed for instance in Scotland since April 2018 as part of the Equality Act 2010: this duty, referred to as the 'Fairer Scotland Duty', imposes on a number of public bodies in Scotland the duty to 'actively consider ("pay due regard" to) how they can reduce inequalities of outcome caused by socio-economic disadvantage when making strategic decisions' ${ }^{30}$ In practice, this means that decisions such as where to locate a school or a hospital or how to develop a neighborhood

25 CESCR (n 19) para 35.

26 Angelo Capuano, "The Meaning of "Social Origin" in International Human Rights Treaties: A Critique of the CESCR's Approach to "Social Origin" Discrimination in the ICESCR and its (Ir) relevance to National Contexts such as Australia' (2017) 41 NZJ Empl. Relations 105.

27 ibid 106.

28 ibid 109-10.

29 HRC, 'CCPR General Comment No. 18: Non-discrimination' (10 November 1989); CESCR (n 19) para 8 .

${ }_{30}$ Scottish Government, 'The Fairer Scotland Duty Interim Guidance for Public Bodies' (March 2018), <www.gov.scot/binaries/content/documents/govscot/publications/advice-and-guidance/2018/03/ 


\section{Research handbook on human rights and poverty}

should be made with the involvement of the local community and aim at reducing, rather than increasing, the exclusionary impacts of lack of income - thus contributing to a more inclusive, less divided society. ${ }^{31}$

Human rights impact assessments serve to alert policy-makers to the impacts on human rights of the poor of the policies they design and implement. ${ }^{32}$ They are distinct from other types of assessments, including social impact assessments or sustainability impact assessments. The specificity of human rights impact assessments is that they examine the intended and unintended impacts of policy measures on the ability of the States parties to these agreements to respect, protect and fulfil the human rights of people living in poverty. They therefore should be based explicitly on the normative content of human rights, as clarified by the judicial and non-judicial bodies that are tasked with monitoring compliance with human rights obligations. References in impact assessments to development goals or to poverty are therefore not a substitute for a reference to the normative components of human rights. Human rights impact assessments also require reliance on disaggregated data to measure impacts; ${ }^{33}$ the impacts should be measured through diverse methodologies, including methodologies based on the participation of the poor, using both quantitative and qualitative indicators.

The requirement of non-discrimination against the poor is especially important where States face an economic or financial crisis and adopt fiscal consolidation (so-called 'austerity') programmes in order to reassure their creditors as to the health of their public budgets. In a letter to States parties in 2012, the Chairperson of the CESCR emphasized that fiscal consolidation policies 'must not be discriminatory and must comprise all possible measures, including tax measures, to support social transfers to mitigate inequalities that can grow in times of crisis and to ensure that the rights of the disadvantaged and marginalized individuals and groups are not disproportionately affected'. ${ }^{34}$ The duty to ensure austerity programmes shall not negatively impact people in poverty is also emphasized in the Guiding Principles on Extreme Poverty and Human Rights. ${ }^{35}$ The Guiding principles on human rights impact assessments of economic reforms presented in 2018 by the Independent Expert on foreign debt and human rights provide further guidance as to how the such human rights impacts should be conducted. ${ }^{36}$

fairer-scotland-duty-interim-guidance-public-bodies/documents/00533417-pdf/00533417-pdf/govscot \%3Adocument/00533417.pdf $>$ accessed 2 July 2020.

31 One telling example is the relocation of the Monklands University Hospital in North Lanarkshire. After plans were announced for the University Hospital to move, concerns were expressed during consultations that low-income families in the vicinity of the existing hospital might not be able to travel to the new location to seek treatment. A compromise was struck, providing for some primary health care services to remain in Monklands. (Personal communication with Diana Skelton, ATD Fourth World, April 2020).

32 Such a tool is under development within the Belgian Service to Combat Poverty, Insecurity and Social Exclusion: see for details (in Dutch): <www.armoedebestrijding.be/themaarmoedetoets.htm> accessed 6 December 2020.

33 Guiding Principles (n 7) para 52.

34 See also the Statement adopted by the CESCR, 'Public Debt, Austerity Measures and the International Covenant on Economic, Social and Cultural Rights' (22 July 2016) UN Doc E/C.12/2016/1 para 2.

35 Guiding Principles (n 7) para 54.

36 UNGA, 'Guiding Principles on Human Rights Impact Assessments of Economic Reforms' (19 December 2018) UN Doc A/HRC/40/57. 
The third implication is that the equality requirement goes beyond this negative duty: in cases of entrenched discrimination, States may be under an obligation to adopt special measures to attenuate or suppress conditions that perpetuate discrimination. In human rights law, such measures are legitimate to the extent that they represent reasonable, objective and proportionate means to redress de facto discrimination and are discontinued when substantive equality has been sustainably achieved ${ }^{37}$ Courts have sometimes been suspicious of differential treatment that benefits certain underprivileged groups defined by their ethnicity or gender. This reflects adherence to a formal understanding of equality, resulting in a restrictive reading of non-discrimination law as forbidding the 'sin' of discrimination, rather than as a tool to remedy injustices that have their source in society-wide mechanisms of exclusion. ${ }^{38}$ However, since socio-economic condition is not a suspect ground, courts have been far more open to affirmative action measures taken to improve the situation of those who are economically deprived. In fact, such measures are at the very heart of the construction of welfare states, the main purpose of which is to provide support to those who are excluded by the mechanisms of the market. ${ }^{39}$

States therefore should dedicate greater resources to improve the condition of groups who face systemic discrimination. ${ }^{40}$ They should move up the causality chain and also tackle the underlying causes of social exclusion. Indeed, once it is recognized that 'a great deal of poverty originates from discriminatory practices - both overt and covert', it follows that poverty reduction strategies shall only be fully effective if they also address 'the socio-cultural and political-legal institutions which sustain the structures of discrimination'. ${ }^{41}$ The fight against inequalities, based in particular on social condition, should concern not only the sphere of economic, social and cultural rights, but also the sphere of civil and political rights, since political influence and socio-economic inequalities are mutually reinforcing. ${ }^{42}$

The prohibition of discrimination on grounds of social condition or property therefore has three implications: (1) a negative duty not to disadvantage on those grounds, (2) a positive duty to avoid de facto discrimination, and finally (3) a positive duty to prioritize people who are facing systemic disadvantage, in particular as a result of poverty. These duties can only be effectively discharged if the impacts on people living in poverty are adequately measured, which requires the disaggregation of general development indicators, inter alia, by income.

\footnotetext{
37 CESCR (n 19) para 9.

38 Kathleen M Sullivan, 'Sins of Discrimination: Last Term's Affirmative Action Cases' (1986) 100 Harv. L. Rev. 78.

39 This should be nuanced, since not all welfare states seek to achieve equality: some models only aim at protecting individuals from extreme deprivation, without setting wealth redistribution as an objective in its own right. See Gosta Esping-Andersen, The Three Worlds of Welfare Capitalism (Princeton, NJ: Princeton University Press, 1990).

40 CESCR (n 19) para 39.

41 Principles and Guidelines (n 8) para 21.

42 HRC, 'Report of the Special Rapporteur on Extreme Poverty and Human Rights' (27 May 2015) UN Doc A/HRC/29/31 para 21; United Nations Research Institute for Social Development, 'Combating Poverty and Inequality: Structural Change, Social Policy and Politics' <www.unrisd.org/unrisd/website/ document.nsf/(httpAuxPages)/92B1D5057F43 149CC125779600434441 ?OpenDocument\&panel= additional $>$ accessed 2 July 2020; UNGA (n 21) para 21.
} 


\section{Participation}

Ensuring the participation of the poor in the design of poverty-reduction strategies is key to both their legitimacy and their effectiveness. As noted by the CESCR:

a policy or programme that is formulated without the active and informed participation of those affected is most unlikely to be effective. Although free and fair elections are a crucial component of the right to participate, they are not enough to ensure that those living in poverty enjoy the right to participate in key decisions affecting their lives. ${ }^{43}$

The Guiding Principles on extreme poverty and human rights provide that:

States must ensure the active, free, informed and meaningful participation of persons living in poverty at all stages of the design, implementation, monitoring and evaluation of decisions and policies affecting them. This requires capacity-building and human rights education for persons living in poverty, and the establishment of specific mechanisms and institutional arrangements, at various levels of decision-making, to overcome the obstacles that such persons face in terms of effective participation. Particular care should be taken to fully include the poorest and most socially excluded persons. ${ }^{44}$

Low levels of education, lack of self-confidence, poor access to information, the difficulty to organize collectively, time poverty, and lack of trust in the officials or institutions organizing the consultation are all important obstacles that poor people face in exercising their right to take part in the conduct of public affairs. Yet, ensuring such effective participation is the only way to break the vicious cycle in which poor people are underrepresented in decision-making and therefore the policies do not prioritize removing the obstacles they face, resulting in further economic marginalization and, thus, in their political disempowerment.

The Guiding Principles on extreme poverty and human rights also note that anti-poverty strategies and plans of action

should be devised and periodically reviewed through a transparent, inclusive, participatory and gender-sensitive process. The process by which the strategy and plan of action are devised, and their content, should pay particular attention to vulnerable or marginalized groups. States should define and publicize opportunities for participation and information about proposed policy measures should be disseminated widely and in an accessible manner. ${ }^{45}$

Such participation is certainly not a substitute for ensuring that the poor are protected from discrimination in the exercise of civil and political rights (such as freedom of assembly, freedom of association, freedom of expression and the right to vote), which ensure accountability and allow participation in the polity in general. But it is key to understand the real obstacles the poor face and to identify the solutions that are best suited to their circumstances.

The best recent example of the role of participation in improving our understanding of poverty is the Hidden Dimensions of Poverty research project, co-led by ATD Fourth World and Oxford University, involving 1,091 participants across six countries (including 665 adults and children in poverty), both from the North (France, the United Kingdom and the United

43 CESCR (n 5) para 12.

44 Guiding Principles (n 7) para 38.

45 ibid para 104. 
States) and from the South (Bangladesh, Bolivia and Tanzania). ${ }^{46}$ The report was based on a 'Merging of Knowledge' methodology (Croisement des savoirs et des pratiques), defined as a process in which academics, practitioners (activists, social workers) and people in poverty first build knowledge independently in peer meetings and then merge these various sources of knowledge in order to develop new insights into poverty. The process recognizes and values the specific understanding gained from the experience of poverty and exposes each participant to the knowledge and experience of others 'in order to build knowledge that is more complete and greater than the sum of its parts' ${ }^{47}$ The process led to the identification of six 'hidden dimensions' of poverty. These dimensions are called 'hidden' because they go beyond the more classic forms of deprivation referred to both in the money-metric and in the multidimensional approaches to poverty. The first three dimensions relate to what the research describes as the core experience of poverty, a mix of anguish and agency. These are (1) 'suffering in body, mind and heart' ('experiencing intense physical, mental and emotional suffering accompanied by a sense of powerlessness to do anything about it'), (2) 'disempowerment' (defined as 'lack of control and dependency on others resulting from severely constrained choices'), and (3) 'struggle and resistance' (the 'ongoing struggle to survive, which includes resisting and counteracting the effects of the many forms of suffering brought by privations, abuse, and lack of recognition').

The three other dimensions are relational: (4) social maltreatment ('people in poverty are negatively perceived and treated badly by other individuals and informal groups', 'behaviour towards people in poverty is characterized by prejudicial negative judgements, stigma and blame'), (5) institutional maltreatment ('the failure of national and international institutions, through their actions or inaction, to respond appropriately and respectfully to the needs and circumstances of people in poverty, and thereby to ignore, humiliate and harm them'), and (6) unrecognized contributions ('The knowledge and skills of people living in poverty are rarely seen, acknowledged or valued. Often, individually and collectively, people experiencing poverty are wrongly presumed to be incompetent'). These are 'relational' because they result from how people who are not living in poverty affect the lives of people in poverty, either by ignorance or by prejudice. This links these hidden dimensions of poverty with a definition of poverty based on 'social exclusion': underlying both is the idea that poverty does not have its source in the failings of the person living in poverty but rather in the inadequate design of institutions or policies that continue to tolerate the intergenerational transmission of poverty, ignore qualifications acquired by practice rather than formally recognized in diplomas, or undervalue the innovations from people in poverty, particularly the solidarity mechanisms they establish to cope with deprivation.

The Hidden Dimensions of Poverty research illustrates how participation is important not only for the design and implementation of poverty reduction strategies but also to guide the methodological choices concerning data collection and poverty measurement. Indeed, as noted

\footnotetext{
46 R Bray and others, The Hidden Dimensions of Poverty (Montreuil: Fourth World Publications, 2019).

47 Fourth World-University Research Group, The Merging of Knowledge: People in Poverty and Academics Thinking Together (University Press of America, 10 August 2007); Guidelines for the Merging of Knowledge and Practices when Working with People Living in Situations of Poverty and Social Exclusion <www.4thworldmovement.org/wp-content/uploads/2013/05/Guidelines_for the _Merging_of_Knowledge_and_Practices.pdf $>$ 5, accessed 6 December 2020.
} 
by the Special Rapporteur on the right to adequate housing, those concerned 'are best placed to ensure that methods of measurement are accurate and inclusive and at the same time sensitive to their circumstances' ${ }^{48}$ In order to ensure such participation is effective, human rights mechanisms, including national human rights institutions, should cooperate with national statistical offices, to ensure that the methodologies adopted in a country to measure poverty are adequately informed by the experiences of the poor. ${ }^{49}$ It is to this question of measuring poverty that we now turn.

\section{THE HUMAN RIGHTS-BASED APPROACH TO MEASURING POVERTY}

There are three reasons why an adequate measurement of poverty is essential to the effectiveness of poverty reduction strategies. ${ }^{50}$ First, measuring poverty allows the issue of poverty to remain visible and to be kept on the top of the political agenda by more informed voters. Second, disaggregated data provides a guide to action and allows poverty-reduction measures to be better targeted. Regulations or policies that might result in worsening inequalities or exclusion can only be identified and improved if poverty is properly measured. Finally, poverty measurement and monitoring serve to assess the outcomes of poverty reduction strategies and interventions, thereby allowing opportunities to improve the effectiveness of poverty-reduction strategies as well as our understanding about the various mechanisms that perpetuate poverty.

However, apart from references to independent monitoring and to the use of disaggregated data, ${ }^{51}$ as well as to the need to define the attributes of poverty through participatory processes,${ }^{52}$ the consensus documents are less explicit about how poverty is to be measured. Four key principles should be kept in mind in the design of poverty measurement tools.

\section{A. Measure Not Only the Number of the Poor, but Who the Poor Are}

The Principles and Guidelines emphasize that 'the objective of the exercise should not merely be to come up with a number, such as the percentage of poor people in the population, but to ascertain who these people are and how poor they are' and to identify, within the poor, those who are 'especially deprived and marginalized'. ${ }^{53}$ This is another reason why the disaggregation of data related to poverty and social exclusion matters in a human rights perspective: in addition to identifying potential instances of discrimination, as discussed above in Section I, it allows for identifying who is poor, taking into account characteristics such as sex, age, ethnic origin, nationality, disability, or place of residence in particular. This allows more targeted action to be taken towards the groups affected and serves to identify which interventions

\footnotetext{
48 UNGA (n 21) para 73.

49 OHCHR, 'Everyone Counts: Ensuring a Response of Official Statistics to Sustainable Development Goals Consistent with Human Rights' (8 May 2015) UN Doc. ECE/CES/2015/35 para 7 (c).

50 UN Economic Commission for Europe, 'Guide on Poverty Measurement' (2017) UN Doc ECE/ CES/STAT/2017/4 para 20.

51 Guiding Principles (n 7) para 105.

52 Principles and Guidelines (n 8) para 33.

53 ibid paras $35-36$.
} 
shall be the most effective. It is also a first condition towards understanding the structural determinants of poverty, i.e., the processes of social exclusion that lead to people becoming and remaining poor.

Identifying who the poor are also allows for distinguishing between transient and chronic poverty. ${ }^{54}$ Indeed, it is only by asking who the poor are that statistical offices and other actors can assess whether the poor in year one are the same as the poor in year zero or in year two. This is important information to guide policies, since transient and chronic poverty call for very different poverty-reduction approaches, and since only longitudinal data allow for understanding the exclusionary processes leading to poverty. ${ }^{55}$

\section{B. Design Specific Methodologies to Identify the 'Missing Poor'}

Measuring certain dimensions of poverty may pose specific challenges, particularly where the groups concerned are difficult to include in surveys covering a sample of the general population. ${ }^{56}$ This is the case in particular for institutionalized people (in elderly care homes, children's homes, and mental health institutions), for undocumented migrants or for homeless people, as well as for street children. ${ }^{57}$ For some groups, such as street children or irregular migrants, 'being identified by government authorities may be threatening, ${ }^{58}$ and this may impede proper data collection. Other factors may also play a role. Data on homelessness, for instance, is scarce in most countries not only because governments may prefer not to be held accountable but also because of the sheer difficulty of collecting such data.

Yet, without accurate measurement of poverty across all groups, an accountability gap emerges and the effectiveness of poverty reduction strategies is significantly reduced. The invisibility of certain groups of the population living in poverty or at risk of poverty may lead underdeveloped policies that are ad hoc, temporary or short-term, rather than fully addressing the challenge.

Some good practices are worth noting. Starting in 2011, the Italian statistical office Istat teamed with the Ministry of Education and Social Policy, the Italian Federation of Associations for the Homeless (fio.PSD), and the charity Caritas, to develop an understanding of how many people were homeless in Italy and who they were. ${ }^{59}$ After the shelters and canteens serving homeless people were identified in 158 municipalities, interviews were conducted during a one-month period, individual diaries were kept to reduce the risk of double counting people using multiple services during the month. In total, 50,724 homeless people were estimated to have used at least one of the services during the November-December 2014 period, representing a small increase over 2011 results. Researchers also found a larger proportion had been homeless for at least three months ( 83 per cent) and for more than two years (41 per cent) compared to 2011. The survey suggested that the vast majority of the homeless were men ( 85.7 per cent), foreigners (58.2 per cent), and living alone (76.5 per cent).

\footnotetext{
54 Michael Hoy, Brennan Scott Thompson, Buhong Zheng, 'Empirical Issues in Lifetime Poverty Measurement' (2012) 10(2) J Econ. Inequality 163-89.

55 United Nations Economic Commission for Europe (n 50) para 81.

56 Roger Tourangeau and others (eds), Hard-to-Survey Populations (Cambridge: CUP, 2014).

57 United Nations Economic Commission for Europe (n 50) paras 428-32.

58 Committee on the Rights of the Child (CRC), 'General Comment No. 21 (2017) on Children in Street Situations’ (21 June 2017) UN Doc CRC/C/GC/21 para 72.

59 United Nations Economic Commission for Europe (n 50) 30-31.
} 


\section{Research handbook on human rights and poverty}

An important limitation of this approach is that the study relied on night shelters and canteens. The method was deemed more feasible than conducting surveys in public spaces (parks) where the homeless may also be found, however it gives a biased picture of the reality of homelessness, since some homeless people, especially families and women, may not visit shelters nor eat at canteens, relying instead on the solidarity of neighbors or extended family. ${ }^{60}$

Various proposals have been made to overcome such limitations. ${ }^{61}$ In order to increase the rate of response from the poorest households, the questionnaires should be simplified, and the option should be offered to answer only certain questions. In addition, the interviewers should be better trained to support the interviewees in answering complex questions such as those related to income levels. The more experienced interviewers should identify good practices that could improve response rates, for instance in the way the initial contact is made or in the kind of support provided to the persons surveyed. As regards specifically the 'missing poor' - people living in institutions, caravan dwellers or homeless people, or undocumented migrants - surveys complementary to household surveys should be conducted at regular intervals, in close collaboration with the social services. In Belgium, the methodology was tested to reach homeless people and undocumented migrants (particularly difficult to reach due to both to language barriers and to their fear of contacts with public authorities). As noted by the research team, 'the fact that this has worked in two target groups that are very hard to reach suggests that it should also work with other target groups, provided the required resources and preparation are envisaged for this'. ${ }^{62}$

Fear of seeking out social services may be one particularly disturbing reason why poor households are underrepresented in general surveys. Indeed, in addition to the examples above, poor families may be reluctant to engage in such surveys because of the precariousness of their living conditions. This may be especially the case where social services may threaten to remove children from their families due to poor living conditions. A vicious cycle may emerge: because a family fears that the social services will recommend removing the children from the household, it may seek to evade contacts with such services, and with administrative agents in general, including with surveyors. This may be one major reason why poor households are underrepresented in general surveys, albeit one that is generally overlooked. It may be seen as the reverse of the 'service statistics paradox', according to which the poor that are supported by social services (for instance, homeless people that are accommodated in shelters, as opposed to those living on the streets) tend to be overrepresented in statistics, leading to another distortion in the data guiding poverty reduction strategies. ${ }^{63}$

${ }^{60}$ As noted by the Special Rapporteur on adequate housing: 'Homelessness among single men living on the streets or using emergency shelters is more easily measured. It is more difficult to measure homelessness among women, children and young people living temporarily with family or friends, or among those most marginalized and precariously housed within informal settlements, who may be altogether left out of census or data collection' (UNGA (n 21), at para. 70).

${ }_{61}$ Ingrid Schockaert and others, 'Poverty Between the Cracks. Complements and Corrections to EU-SILC for Hidden Groups of Poor People' (May 2012) Belgian Federal Science Policy Office (BELSPO).

62 ibid 6.

${ }^{63}$ G Tipple and S Speak, The Hidden Millions: Homelessness in Developing Countries (London: Routledge, 2009). 


\section{Combine Quantitative Data with Qualitative Data}

While quantitative data about all groups facing poverty are of course important both for purposes of accountability and to ensure poverty reduction strategies work effectively, numbers alone may not suffice. Such quantitative estimates should be complemented by qualitative assessments of poverty, as experienced by people living in poverty. This was the intuition at the heart of the 'Voices of the Poor' project launched in the late 1990s. ${ }^{64} \mathrm{It}$ is also a lesson that emerges within the UN human rights system. Thus, in her 2015 report on homelessness, the Special Rapporteur on the right to adequate housing relied on conclusions of the Institute of Global Homelessness ${ }^{65}$ to underline 'the critical importance of qualitative evidence, including, for example, oral testimony, photographs or videos. A human rights-based measurement of homelessness should focus on prevention and on addressing underlying causes, and qualitative information capturing actual experiences often reveals more about how to prevent or solve it than numbers alone'. ${ }^{66}$ The Office of the High Commissioner for Human Rights makes a similar point: 'For the smallest groups or those invisible in official statistics, new partnerships and use of innovative technology and statistical techniques, including mapping, targeted surveys, small area estimation may be required'. ${ }^{67}$

The experience of people living in poverty cannot be adequately reflected solely in statistical data. Such data should be complemented by other means to convey information to provide different framings and narratives both to policy-makers and to the broader public, in order to improve the salience of poverty in public discourse and to broaden political imagination. ${ }^{68}$

There are two major advantages to this. First, if achieved through the participation of the poor - allowing for the emergence of a plurality of narratives - it can support the poor in becoming more reflective about their predicament. This contributes to empowerment and capacity-building, especially in circumstances where, as described by the World Development Report 2015, poverty ends up generating its own taxes due to the obstacles that poor people face in imagining different futures for themselves and to the cognitive limitations poverty entails. ${ }^{69}$ Poverty, this report notes, 'is not simply a shortfall of money. The constant, day-to-day hard choices associated with poverty in effect tax an individual's bandwidth, or mental resources. This cognitive tax, in turn, can lead to economic decisions that perpetuate poverty'.$^{70}$ This is because poverty leads one to focus on the present (the satisfaction of immediate needs) to the detriment of the future (planning in the longer term); because the poor may find it difficult to aspire to another future, and thus to 'take advantage of the opportunities that

64 D Narayan and others, Can Anyone Hear Us? Voices from 47 Countries (Oxford: OUP, 1999); D Narayan and others, Voices of the Poor. Crying out for Change (Oxford: OUP, 2000).

${ }_{65} \mathrm{~V}$ Busch-Geertsema and others, 'A Global Framework for Understanding and Measuring Homelessness’ (July 2016) 55 Habitat International 124.

66 UNGA (n 21) para 72.

67 OHCHR (n 49) para 7 (a).

68 On the importance of such framing, see George Lakoff, The Political Mind. A Cognitive Scientist's Guide to your Brain and its Politics (Penguin Books: New York, 2008); World Bank, 'World Development Report 2015: Mind, Society and Behaviour' (2015) <www.worldbank.org/en/publication/ wdr2015> accessed 2 July 2020.

69 ibid ch 4; J Haushofer and E Fehr, 'On the Psychology of Poverty' (23 May 2014) 344 Science $862-67$.

70 ibid 81 (based on S Mullainathan and E Shafir, Scarcity: Why Having Too Little Means So Much (New York: Times Books, 2013). 
do present themselves'; ${ }^{71}$ and because, finally, 'the environments of people living in poverty make additional cognitive demands', especially in poor countries where infrastructures are weak or non-existent. ${ }^{72}$ Mapping poverty by taking into account the voices of the poor can help to gradually overcome these obstacles, since the alternative narratives that emerge should make it easier for them to reflect about their predicament and permit policymakers to adopt a more realistic view of poverty and of the traps, including the cognitive traps, into which the poor may fall. The participation of the poor, the design of a plurality of methodologies to measure poverty, and capacity-building are mutually reinforcing and, combined, can form a virtuous cycle.

The second contribution of a qualitative approach to poverty based on the experience of people living in poverty is that such an approach is much more appropriate to identifying the relational dimensions of poverty, i.e., the constraints that have their source in agency/social relations, often trapping people in poverty. ${ }^{73}$ Understood as a process of social exclusion, poverty can only be adequately described based on the dynamic of how poverty is caused and perpetuated, as experienced by the people affected. By adopting what anthropologists call an 'emic' perspective, as opposed to the 'etic' perspective of the external observer, additional issues are identified such as disempowerment by local elites and traditional authorities, shame leading the destitute to cut themselves off from social relationships that could provide a way out of poverty, or the weight of cultural norms related to gender, to loyalty towards one's family members or to gestures of solidarity towards the community.

There is therefore a link, real although indirect, between the methodologies used to capture poverty on the one hand, from the most expert-driven, quantitative and 'objective', to the most participatory, qualitative and 'subjective', and the definition of poverty on the other hand, from the most money-centric to the most attentive to the process of social exclusion. Table 1.1 seeks to capture this relationship. It is based on typologies of poverty measurement tools developed by Andrew Martin Fischer, ${ }^{74}$ on the 'Merging of Knowledge' methodology developed by ATD Fourth World ${ }^{75}$ and on the contrast between quantitative and qualitative approaches to poverty drawn by Jones and Tvedten in their study of poverty in Mozambique. ${ }^{76}$ The table aims to ask the question of how we should understand the complementary ways in which poverty is defined and assessed. Jones and Tvedten take the view that:

while quantitative and qualitative approaches overlap somewhat in their recognition of the material aspect to poverty, their understandings of what poverty is and the mechanisms that produce it are distinct. Consequently, a forced marriage of qualitative and quantitative approaches into an integrated

71 ibid. Arjun Appadurai has most explicitly put forward the argument that strengthening the 'capacity to aspire' can be an essential tool in the fight against poverty. He conceived of the 'capacity to aspire' as 'a cultural capacity', which could be an ally in development, since 'the poor could find the resources required to contest and alter the conditions of their own poverty'; A Appadurai, 'The Capacity to Aspire: Culture and the Terms of Recognition', in V Rao and M Walton (eds), Culture and Public Action (Stanford: Stanford University Press, 2004) 59-84.

72 ibid.

73 S Jones and I Tvedten, 'What Does it Mean to be Poor? Investigating the Quantitative-Qualitative Divide in Mozambique’ (2019) 117 World Development 158.

74 Fischer (n 2).

75 Bray et al (n 46).

76 Jones and Tvedten (n 73). 
Table 1.1 Relationship between definition of poverty and methodologies for measurement

\begin{tabular}{|c|c|c|c|c|}
\hline & & \multicolumn{2}{|l|}{ Etic } & \multirow{2}{*}{$\begin{array}{l}\text { Emic } \\
\text { People in poverty }\end{array}$} \\
\hline & & Academic experts & Practitioners & \\
\hline \multirow[t]{2}{*}{ Static } & Money-metric & $\begin{array}{l}\text { Income-based measures of } \\
\text { poverty relying on a price } \\
\text { assessment of basic needs }\end{array}$ & & \\
\hline & Multidimensional & $\begin{array}{l}\text { Entitlements-based approaches } \\
\text { based on a multidimensional } \\
\text { understanding on poverty }\end{array}$ & & \\
\hline Dynamic & Social exclusion & & & $\begin{array}{l}\text { Participatory methodologies such } \\
\text { as the reconstruction of the chain } \\
\text { of events that led to a situation of } \\
\text { poverty (histograms), the mapping } \\
\text { of power relationships within the } \\
\text { community, and wealth ranking } \\
\text { (perception within the community } \\
\text { of different categories of 'wealthy' } \\
\text { and 'poor' people) }\end{array}$ \\
\hline
\end{tabular}

analysis, risks losing the inherent diversity of perspectives and types of knowledge that comes from different ways of seeing poverty. ${ }^{77}$

In contrast, the 'Merging of Knowledge' approach pioneered by ATD Fourth World is premised on the idea not only that the knowledge of experts, of practitioners and of people with an experience of poverty are complementary and bring different insights to the understanding of poverty, but that they can be brought together to provide a new form of knowledge, the result of the 'merger' - of what Jones and Tvedten call 'forced marriage'. Are these approaches conflicting? Perhaps not, if we consider that the knowledge of each category of actors, and the associated methodology, has a distinct function to fulfil, but that a separate and perhaps richer understanding can emerge from trying to combine them. Improvements in quantitative indicators measuring poverty could be related, for instance, with processes of empowerment (can empowerment explain improvements in the material conditions of the poorest segments of the population?), or quantitative data showing the increase in inequalities despite overall economic growth and improvement of material conditions could be a powerful tool to create awareness of the inequitable nature of growth (should growth not be better shared?): in such processes, the fusion of knowledges and the combination of methodologies is the source of new insights in the process of poverty creation, with a strong potential for empowerment.

\section{Measure Not Only Theoretical Access to Rights, but also the Non-take-up of Rights}

The phenomenon of the non-take-up of rights (whether in the form of benefits or of services) should be given specific treatment in poverty measurement, in order to understand better why

77 ibid 164. 
potential beneficiaries of support schemes do not claim their rights and what can be done about this. ${ }^{78}$ Specific indicators should be designed that focus not only on the effective enjoyment of the right (social security, housing, education, healthcare, food) or only on the legal entitlements provided, but on the gap between the two.

Why is it that certain people do not claim what they have a right to, or do not rely on certain services that are in principle available to them $?^{79}$ This may be because of a lack of information about their rights; because of the bureaucratic hurdles (especially as compared to the level and unpredictability of the benefits) $;{ }^{80}$ because they need an urgent solution and cannot afford to wait; because of a lack of trust in the relevant authorities; ${ }^{81}$ because of the so-called 'welfare stigma', especially where the scheme is based on fine targeting; because they consider that they will not be able to prove the lack of income; because they believe they will not be able to comply with conditionalities attached to the benefit; or finally, because of a vicious cycle in which the lack of access to a certain right (such as housing) leads to a denial of other rights (such as education). ${ }^{82}$

Which lessons can be drawn from the non-take-up of rights in designing poverty measurement tools? As explored above, a human rights-based approach to poverty reduction should combine the use of structural, process and outcome indicators, assessing the legal/regulatory and institutional framework, the efforts of public authorities (including budgetary commitments), and the results achieved. In principle, this combination should identify gaps between accessibility in theory of certain benefits, as measured by structural and process indicators, and their enjoyment in fact, as measured by outcome indicators. That information alone, however, will be insufficient to identify the solutions that can help overcome the gap. As noted above, it is only by complementing statistical data with narratives from the poor themselves that the reasons for non-take-up can be identified and public policies be made more effective.

\section{CONCLUSION}

Poverty-reduction efforts will only be as effective as the poverty measurement tools on which we rely. Precise measurement is essential to track progress and improve accountability, to

78 See Odenore, 'Welcome to the Observatory on Non-Take Up (NTU) of Social Rights and Public Services' at <https://odenore.msh-alpes.fr/en/content/welcome-observatory-non-take-ntu-social-rights -and-public-services> accessed 2 July 2020; Antoine Math, 'Non-Recourse in France: A Real Problem, A Limited Interest' (1996) Research and Forecast; W Van Oorschot, 'Failing Selectivity: On the Extent and Causes of Non-take up of Social Security Benefits' in HJ Andress (ed), Empirical Poverty Research in Comparative Perspective (Aldershot: Ashgate, 1998) 101-32.

79 Natascha Van Mechelen and Michiel Van Der Heyden, 'The Fight Against Non-Take Up: An Inventory of Policy Measures and Reflection in the Light of Literature Scientific and Experiments of Politics in the UK and Sweden' (October 2017) Policy Brief No. 1/2017; W Van Oorschot, Take it or Leave it: a Study of Non-take-up of Social Security Benefits (Tilburg: Tilburg University Press, 1994); F De Boe and others, Poverty and Ineffectiveness of Rights. Non-take-up of Rights (Brussels: Die Keure / La Charte, 2017).

80 Philippe Warin, 'What is the Non Take-up of Social Benefits?' (Books and Ideas 9 June 2014).

81 UNGA, 'Report of the Special Rapporteur on the Human Rights of Migrants' (3 April 2014) UN Doc A/HRC/26/35 para 103.

82 A Catrice-Lorey, 'Inequalities in Access to Social Protection Systems and Cultural Poverty' (1976) 30(4) French J of Social Affairs 127-37. 
ensure that the question of tackling poverty remains high on the political agenda, and to ensure that efforts are adequately focused on the causes of poverty, rather than simply on the symptoms. A human rights-based approach to poverty measurement also requires recognizing that human rights violations and material deprivation are interlinked and seeing poverty as a multidimensional phenomenon that cannot be reduced to income poverty but instead is a set of deprivations in access to health, education and housing, and worsened by political disempowerment. But the human rights-based approach to poverty measurement goes beyond that: it calls for using a range of methodologies in combination, including participatory methodologies, which are best suited to highlight power relationships and the causal links that lead to poverty and its reproduction.

This chapter emphasizes three major benefits of approaching poverty reduction as a human rights issue. First, using the human rights lens emphasizes that the reduction of poverty, which is both the cause and consequence of human rights violations, is not a matter of choice for the State, but a duty, grounded in human rights. Therefore, accountability mechanisms should be built into the poverty reduction strategy, including independent monitoring of progress.

Second, a human rights-based approach to poverty reduction should include a component related to equality and non-discrimination. This requires not only an explicit protection from discrimination on grounds of social (or social and economic) condition but also the disaggregation of data concerning access to the basic goods and services that correspond to the full enjoyment of human rights (housing, education, healthcare, food, work and social security) by income, gender, age, race, ethnicity, nationality, migratory status, disability, educational background, geographic location and other characteristics relevant in national context. If such disaggregated data reveal disparities in outcomes, targeted policies should be adopted to close the gaps.

Third, the design and implementation of poverty reduction strategies, and the methodological choices concerning data collection and poverty measurement, should be informed by the participation of the poor. This can be time-consuming and demanding, but it is the only way to ensure that the strategies and measurements are sufficiently inclusive and well informed by the experience of those living in poverty or at risk of poverty or social exclusion. Indeed, poverty as social exclusion cannot be adequately understood otherwise.

This leads to several specific recommendations for the measurement of poverty. Such measurement should allow for arriving not at a single figure (such as the percentage of the population at risk of poverty or the absolute number of people facing severe material deprivation), but also at an improved understanding of the causes of poverty in accordance with the multidimensional nature of poverty. It should also allow, by an adequate disaggregation of data, for identifying who the poor are, and for unpacking the processes through which poverty is caused and perpetuated. In measuring poverty, particular care should be taken not to ignore the 'missing poor', i.e., the groups that tend to be invisible in statistics, for instance because they are not covered by household surveys or because they avoid contacts with social services. This requires the use of a plurality of methodologies to collect data about poverty, going beyond the classic reliance on household surveys.

Numbers alone may not suffice to convey the actual experiences of the poor - the circumstances in which they live, the obstacles they encounter, and the solutions they imagine for themselves. Statistical data should be complemented by other sources of information about poverty, providing other framings and narratives, ideally coming from the poor themselves. Finally, because it is not unusual for the poor not to take up the financial benefits they could 
claim, or not to use the services accessible to them, even when such services are free or affordable, it is essential that poverty measurement efforts focus on the non-take-up of rights. The phenomenon should be given specific treatment in poverty measurement, in order to understand better why potential beneficiaries of support schemes do not claim their rights and what can be done about this. In the setting of political priorities and in designing public programmes, only what is counted matters: we should ensure that, in the future, the poor count more. 